Heike K. Lotze $\cdot$ Karsten Reise

\title{
Ecological history of the Wadden Sea
}

Published online: 18 December 2004

(C) Springer-Verlag and AWI 2004

Historical ecology is a new, interdisciplinary field concerned with the reconstruction and understanding of past ecosystems and their changes through time. The ecological history of an ecosystem determines its present state and influences its path into the future. Thus, without knowing their past we cannot understand how ecosystems function today, we cannot predict future changes, and we cannot effectively protect and restore degraded ecosystems without historical baselines to use as reference points.

During a multi-disciplinary workshop held from 23 to 25 January 2004 at the Wadden Sea Research Station, Sylt, which belongs to the Alfred Wegener Institute of Polar and Marine Research, archaeologists, historians and ecologists jointly explored the ecological history of the Wadden Sea. This unique coastal ecosystem in the southern North Sea was created about 7,500 years ago by retreating glaciers and subsequent sea-level rise. Since then, natural forces have shaped the coastal land- and seascape. However, at least over the past 2,500 years, humans have been a major driver for change in the Wadden Sea through resource exploitation, habitat transformation and pollution. Today, the Wadden Sea is a fundamentally changed ecosystem. But, because most changes happened a long time ago, a vision of "what was natural in the Wadden Sea" is completely lost to living memory.

H. K. Lotze $\cdot$ K. Reise

Alfred Wegener Institute for Polar and Marine Research, Wadden Sea Station Sylt, 25992 List, Germany

H. K. Lotze

Leibniz Institute for Marine Science,

Düsternbrooker Weg 20, 24105 Kiel, Germany

H. K. Lotze $(\square)$

Department of Biology, Dalhousie University,

Halifax, NS, B3H 4J1, Canada

E-mail: hlotze@dal.ca

Tel.: + 1-902-4942478

Fax: + 1-902-4943736
The major goals of our workshop were: (1) to create a vision of the Wadden Sea before large-scale human interference; (2) to compile a comprehensive overview on the history and the causes of ecological changes; (3) to analyze the consequences of multiple human impacts on food-web and ecosystem structure; and (4) to learn from the past in order to inspire public imagination today, and guide conservation and restoration measures in the future. This volume of Helgoland Marine Research contains the papers presented at the workshop in which archaeologists, historians and ecologists summarized the knowledge available in their respective disciplines. A first series of papers reviews human activities and impacts on marine resources over time, such as human settlement and cultural change (Knottnerus), habitat transformation (Reise), exploitation in Medieval Europe (Hoffmann) and recent centuries in the Dutch (Wolff) and Danish (Holm) Wadden Sea, and eutrophication (van Beusekom). A second series of papers reviews changes in species occurrence and abundance from an archaeological perspective (Prummel and Heinrich), and over past centuries and millennia (Lotze). The last paper (Lotze et al.) provides a broad synthesis on what was learned during workshop discussions with respect to the reconstruction of the ecological history of the Wadden Sea, the causes and consequences of ecological changes, and the implications for conservation and management.

This workshop was part of the History of Marine Animal Populations (HMAP, http://www.hmapcoml.org) programme of the Census of Marine Life (http://www.coml.org), a global research effort asking: 'what was, what is and what will be in the oceans?'. We gratefully acknowledge the workshop funding by the Alfred Sloan Foundation, the Alfred Wegener Institute for Polar and Marine Research, and the MARINERS Program of Southern Denmark University. We thank the independent experts for reviewing the manuscripts, and the staff and students of the Wadden Sea Station for their help in organizing the workshop. 